\title{
Examining the Friedman Hypothesis in the Case of Food Inflation: Evidence from Sri Lankan Economy
}

\author{
Selliah Sivarajasingham ${ }^{1}$
}

\begin{abstract}
The relationship between inflation rate and inflation volatility has attracted more attention by theoretical and empirical macroeconomists. Empirical studies on the relationship between food inflation and food inflation variability is scarce in the literature. This study examines the intertemporal dynamic linkages between food price inflation and its volatility in the context of Sri Lanka. The empirical evidence derived from the monthly data for the period from 2003M1 to 2017M12 for Sri Lanka. Food price inflation is defined as log difference of food price series. The volatility of a food price inflation is measured by conditional variance generated by the FIGARCH model. Granger causality tests show that food inflation seems to exert positive impact on inflation variability. Hence, the findings of the study supports the Friedman hypothesis in both cases of consumer food price inflation and wholesale food price inflation. This implies that past information on food inflation can help improve the one-step-ahead prediction of food inflation variability but not vice versa. Our results have some important policy implications for the design of monetary policy, thereby promoting macroeconomic stability.
\end{abstract}

Keywords: Causality, Food inflation, FIGARCH, Inflation volatility

\footnotetext{
${ }^{1}$ Department of Economics \& Statistics, University of Peradeniya, Sri Lanka. Email: ssivaraj@pdn.ac.lk
} 


\section{Introduction}

The knowledge about the linkage between the level of inflation and its associated uncertainty is important for making decision about the priority of either targeting the level of inflation or stabilizing monetary policy in an economy. Following Nobel lecture of Friedman (1977), the relationship between inflation rate and inflation uncertainty has attracted more attention by theoretical and empirical macroeconomists. According to Friedman (1977), high inflation will create political pressure to reduce it, but policy makers may fear recessionary effects and be reluctant to lower inflation, resulting in future inflation uncertainty. Friedman (1977) argued that increased variability of inflation distort relative prices and adds an additional risk to long term contracting. In addition, he asserted that high levels of inflation are costly since they raise inflation variability. Hence it leads to inefficient decisions and decreases in economic growth. In contrast, Cukierman and Meltzer (1986) advocate that inflation uncertainty could lead to inflation and also lower long run economic growth.

Despite the considerable number of empirical research on the relationship between inflation and inflation variability, the empirical literature to date has supplied contradictory evidence on the two hypothesis of Friedman (1977), and Cukierman and Meltzer (1986). In addition, the past literature, to our knowledge, shows that there remain scarce in-depth studies focusing on this issue in the context of food price inflation. Most of the studies have focused on the relationship between general inflation and inflation uncertainty in developed countries. However, there are few studies available on this issue for developing/emerging countries. Therefore, this study intends to fill the gap in the literature. Hence, this study would contribute significantly to the existing knowledge. This study attempts to answer the following questions: (i) are food price inflation and food price inflation volatility stationary series, (ii). Is there evidence to support Friedman hypothesis? (iii) Is there evidence to support Cukierman and Meltzer (1986) hypothesis?

\section{Food Inflation in Sri Lanka-at Glance}

Food is an important element of cost of living index represented by Colombo Consumer Price Index (CPI) in Sri Lanka. Food prices affect an economy in several ways, such as cost of living, investment, and trade balance. As 80 per cent of the households in Sri Lanka spend more than 40 per cent of their income on food (HIES, 2012/13). Food price dynamics play important role in the economy. As food expenditure accounts for larger proportion of consumer price index in Sri Lanka, food price dynamics play important role in general price in the economy. The impact of food price inflation on general (CPI) inflation is substantially larger in Sri Lanka. The contribution of food inflation to general inflation is 77 per cent in December 2017 (CBSL, 2017). It is also noted that Sri Lanka falls in the higher inflation risk area (IMF \& Nomura Global Economics, 2015). Figure 1 shows the impact of rising food prices on CPI inflation in various developed and developing economies. The 
impact of food price increases on CPI inflation is substantially larger in developing countries than in developed countries. Apparently, Sri Lanka, in particular, is located in the higher inflation risk area.

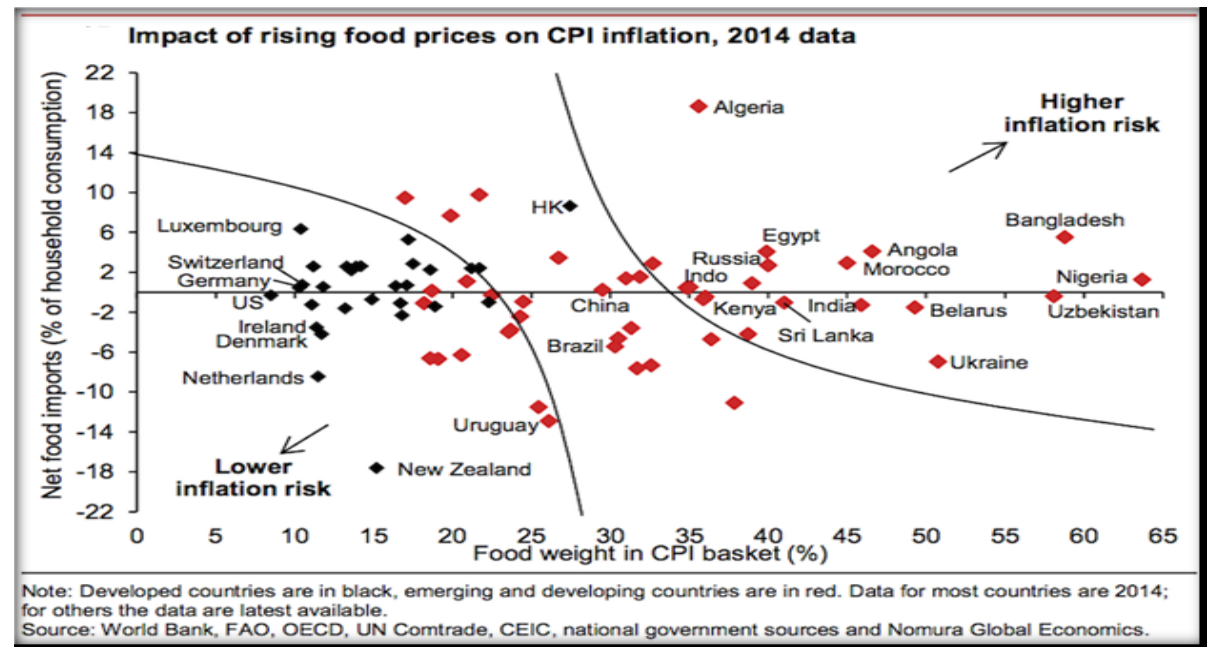

Figure 1: Impact of Rising Food Prices on CPI Inflation, 2014

Source: Adopted from Nomura (2015)

Food price volatility is one of the major concerns for policy makers and development practitioners worldwide. Inflation volatility/uncertainty is not only distort the decisions regarding future saving and investment due to less predictability of real value of future nominal payments, but also extends the adverse effects of these distortions on the efficiency of resource allocation and the level of real activity (Fischer et al., 1981; Golob 1993; Holland 1993). Volatility of inflation, volatility of food price inflation has negative impacts on different financial, and economic variables, political stability hence eventually deteriorate the economic growth and welfare. Volatility of inflation distorts the decision making regarding future saving and investment, the efficiency of resource allocation and the level of real output (Fischer et al., 1981; Golob 1993).

Understanding the dynamics of food price, its volatility and inflation help in planning policy design and policy responses. The high and volatile food price dynamics pose significant challenges for developing countries including Sri Lanka where households spend a larger share of their income on food.

The contribution of this study is threefold. Firstly, this study examine Friedman hypothesis in the case of food inflation and its volatility. Secondly, FIGARCH model which capture long memory property of volatility series is employed to derive a proxy for volatility measures. Thirdly, causality is assessed using bivariate Granger causality method. Thus, the findings of this study can have a number of important policy implications for food production, trade, and monetary policy makers. 
The main objective of the study is to examine Friedman hypothesis in the case of food inflation in Sri Lanka. Friedman's (1977) and Ball's (1992) hypotheses say that higher inflation invokes more inflation uncertainty. In contrast, Cukierman and Meltzer's (1986) hypothesis is that higher inflation uncertainty leads to more inflation. Both these hypotheses are examined using Granger causality tests. The specific objectives are (i) to test the stationarity property of the variables, (ii). To derive conditional variance series from food price inflation using FIGARCH model (iii) to test Friedman-Ball and Cukierman-Meltzer inflation uncertainty hypothesis.

The structure of the paper is as follows. Section 2 describes food inflation at glance in Sri Lanka. Section 3 briefly reviews the literature. Section 4 describes the data and methodology, Section 5 discusses the empirical results. Finally, Section 6 summarizes the main conclusions.

\section{Review of Literature}

There are ample empirical studies that examine the relationship between inflation and inflation variability. Okun (1971) first gave an intuitive explanation for correlation between the level and variability of inflation. Positive association between mean and variance of inflation has been extensively documented in the literature; Okun (1971), Logue and Willet (1976), Tylor (1981), Golob (1994) and Rizvi and Naqvi (2009). Since the 1970s, academics have started to give more attention to the relation between inflation and its temporal variance. There is ample empirical evidence of this relationship in economic literature. However, the theoretical underpinnings of this area have not been rigorously investigated.

Many empirical studies provide evidence of the positive relationship between mean and variance of inflation. For examples, Okun (1971), Logue and Willet (1976), Barro (1976), Friedman (1977), Taylor (1981), Evans (1991), Grier and Perry (1998), Nas and Perry (2000). Cukierman and Wachtel (1979), Taylor (1981), Ball et al., (1990), Golob (1994), Daal et al., (2005) provided evidence in support of the Friedman-Ball hypothesis. In contrast, Cukierman-Meltzer (1986) hypothesis is supported by the findings of Holland (1995), Baillie et al., (1996a), Grier and Perry (1998), Wilson (2006). Existing literature has not yet addressed the relationship in context of food price inflation.

\section{Methods}

\section{Data}

Variables used in the study include are; Colombo Consumer Price Index for Food and non-Alcoholic Beverages (CFPI), Wholesale Food Price Index (WFPI). Two food price indices are used in the study. CFPI were collected from the Department of Census and Statistics, WFPI is collected from 
Central Bank of Sri Lanka. The inflation series of CFPI, WFPI are denoted by INFCFPI, INFWFPI respectively. Data used in the study are monthly data spanning from 2003M1 to 2017M12. All the series are transformed into natural logarithms and inflation is defined as log difference of price series, where $\mathrm{P}$ is price index. Most food price series often admit a non-stationary component, but food price inflation (log difference) seems to be stationary.

The volatility (uncertainty) of a food price inflation is measured by various measures, namely standard deviation/ variance of the series, absolute food price inflation, squared food price inflation, and conditional variance generated by the FIGARCH model. The absolute food inflation, squared food inflation and conditional variance of food inflation generated by FIGARCH model are used as proxies for variability of food inflation. According to the theories of Ball (1992), and Cukierman and Meltzer (1986), inflation uncertainty is the conditional variance of inflation.

\section{Analytical Tools}

This study uses two approaches to examine the relationship (i) graphical method, (ii) inferential method. First, we employ scatter plot with confidence ellipse and locally weighted scatter-plot Smoother (LOESS) regression curve line graph. The second method is Granger causality test.

\section{Unit Root Tests}

Further, the Augmented Dickey Fuller test is carried out, as prerequisite test, to check stationarity property of a variable.

\section{Granger's Causality Test}

Granger causality test is employed to identify the direction of causal relationship between the food price inflation and food inflation variability. Granger causality tests (GCT) are valid for stationary series as standard statistical tests are valid under stationary assumptions. Granger causality from one variable to another means that the conditional forecast for the latter can be significantly improved by adding lagged variables of the former to the information set. Causality is defined as: $X_{t}$ is said not to Granger cause $Y_{t}$ if

$$
E\left(Y_{t+h} \mid J_{t}, X_{t}\right)=E\left(Y_{t+h} \mid J_{t}\right)
$$

Various Granger causality tests are employed to get robust results in this study. They are (i) Pairwise Granger causality test ( $F$ test) from single equation method, F test applied to the joint significance of the sum of the lags of each explanatory variable, (ii) VAR Granger causality/Block Exogeneity Wald Tests (Chi-Square), (iii) VEC Granger causality/Block Exogeneity Wald Tests (Chi-Square) to find the causality relationship between variables. 
Considering two series, $\mathrm{X}_{\mathrm{t}}$ and $\mathrm{Y}_{\mathrm{t}}$, integrated order one, the GC test is in the form as:

$$
\begin{aligned}
& \Delta X_{t}=\alpha_{1}+\sum_{i=1}^{n 1} \alpha_{11, i} \Delta Y_{t-i}+\sum_{j=1}^{m 1} \alpha_{12, j} \Delta X_{t-j}+u_{X, t} \\
& \Delta Y_{t}=\alpha_{2}+\sum_{i=1}^{n 1} \alpha_{21, i} \Delta X_{t-i}+\sum_{j=1}^{m 1} \alpha_{22, j} \Delta Y_{t-j}+u_{Y, t}
\end{aligned}
$$

Where $U_{x, t}$ and $U_{y, t}$ are stationary random processes intended to capture other pertinent information not contained in lagged values of $X_{t}$ and $Y_{t}$. The lag lengths, $n$, and $\mathrm{m}$ are decided by AIC in the study. The series $Y_{t}$ fails to Granger-cause $X_{t}$ if $\alpha 11(\mathrm{j})=0\left(\mathrm{j}=1,2,3, . . \mathrm{m}_{1}\right)$; and the series $X_{t}$ fails to Granger-cause $Y_{t}$ if $\alpha 21(\mathrm{i})=0\left(\mathrm{i}=1,2,3, . . \mathrm{n}_{1}\right)$.

\section{The Fractional Integrated Conditional Heteroscedasticity Model}

Volatility series typically has a fractional value of $\mathrm{d}$. The fractionally integrated GARCH model proposed by Baillie et al., (1996b) is denoted by FIGARCH (p,d,q). FIGARCH model allows accounting for the long memory of volatility within a dynamic framework. The FIGARCH $(1, \mathrm{~d}, 1)$ model assumes the growth variable (inflation) follows as

$$
\pi_{t}=\sigma_{t} \varepsilon_{t}, \quad \text { where } \sigma_{t}>0, \varepsilon_{t} \sim \text { i.i.d. }(0,1)
$$

and

$$
\sigma_{t}^{2}=\omega+\beta \sigma_{t-1}^{2}+\left[1-\beta L-(1-\delta L)(1-L)^{d}\right] \pi_{t}^{2}
$$

FIGARCH process displays short memory for $d=0$. For FIGARCH

model, the persistence of a shock at long lags is proportional to $j^{-d-1}$. Persistence is inversely related to the $d$ for $0<d<1$. This FIGARCH model captures long memory in volatility.

\section{Results and Discussion}

\section{Descriptive Statistics, Correlation Analysis and Unit Root Tests}

Preliminary analysis shows how food inflation and food inflation volatility interrelated. For this purpose, exploratory data analysis (EDA) and unit root test are employed. Figure 1 shows the mean and variance dynamics of food price inflation in Sri Lanka. The mean and standard variance are calculated for each month of the year. This figure reveals that mean and variance of food price inflation move together over time. The variance of food price inflation exceeds the mean of food price inflation most of the time periods. 


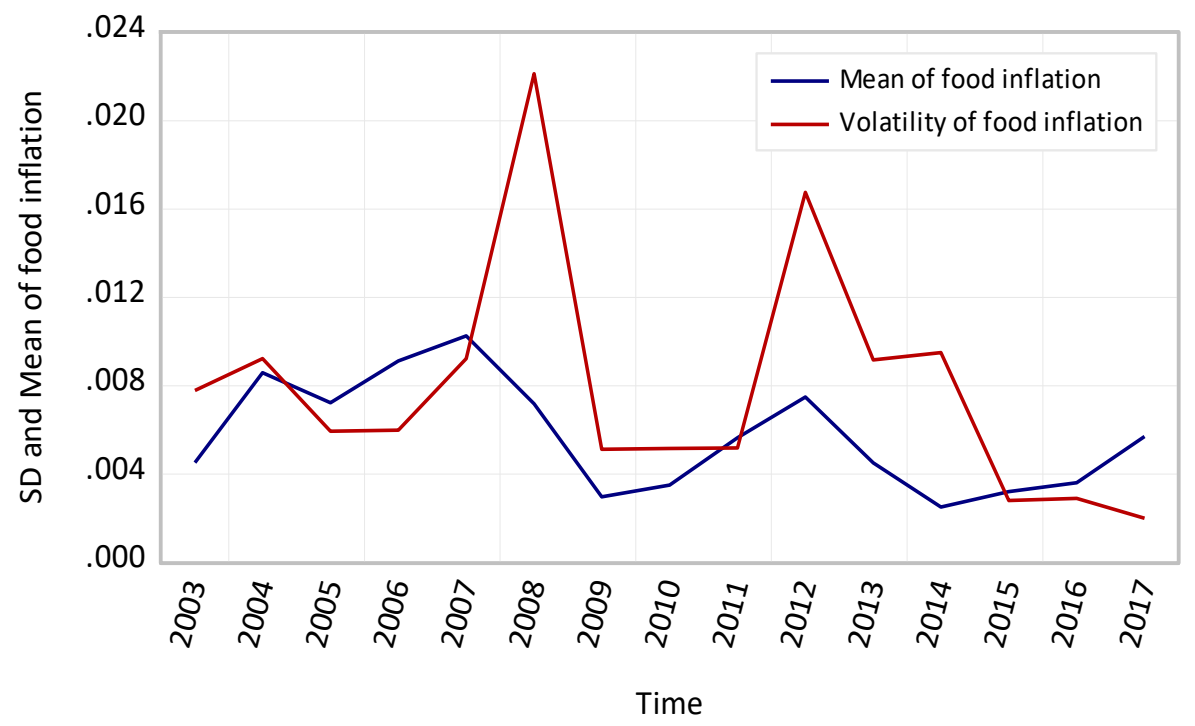

Figure 1: Mean food price inflation and volatility of food price inflation, 2003M1-2014M1

The volatility measures of absolute inflation, squared inflation and conditional variance of food inflation are compared with food inflation trend (Filtered by HP filter). The association is exhibited in the scatter plot with confidence ellipse. They show the positive relationship between food price inflation and variability of the inflation (Figure 2).

The stationarity properties of the inflation and volatility series are examined and presented in Table 1. ADF test shows that food inflation (INFCFPI), wholesale food inflation and conditional variance of food inflation are stationary variables. In contrast, conditional variance of wholesale food inflation (CVWFPI) is nonstationary variable and integrated order one. 

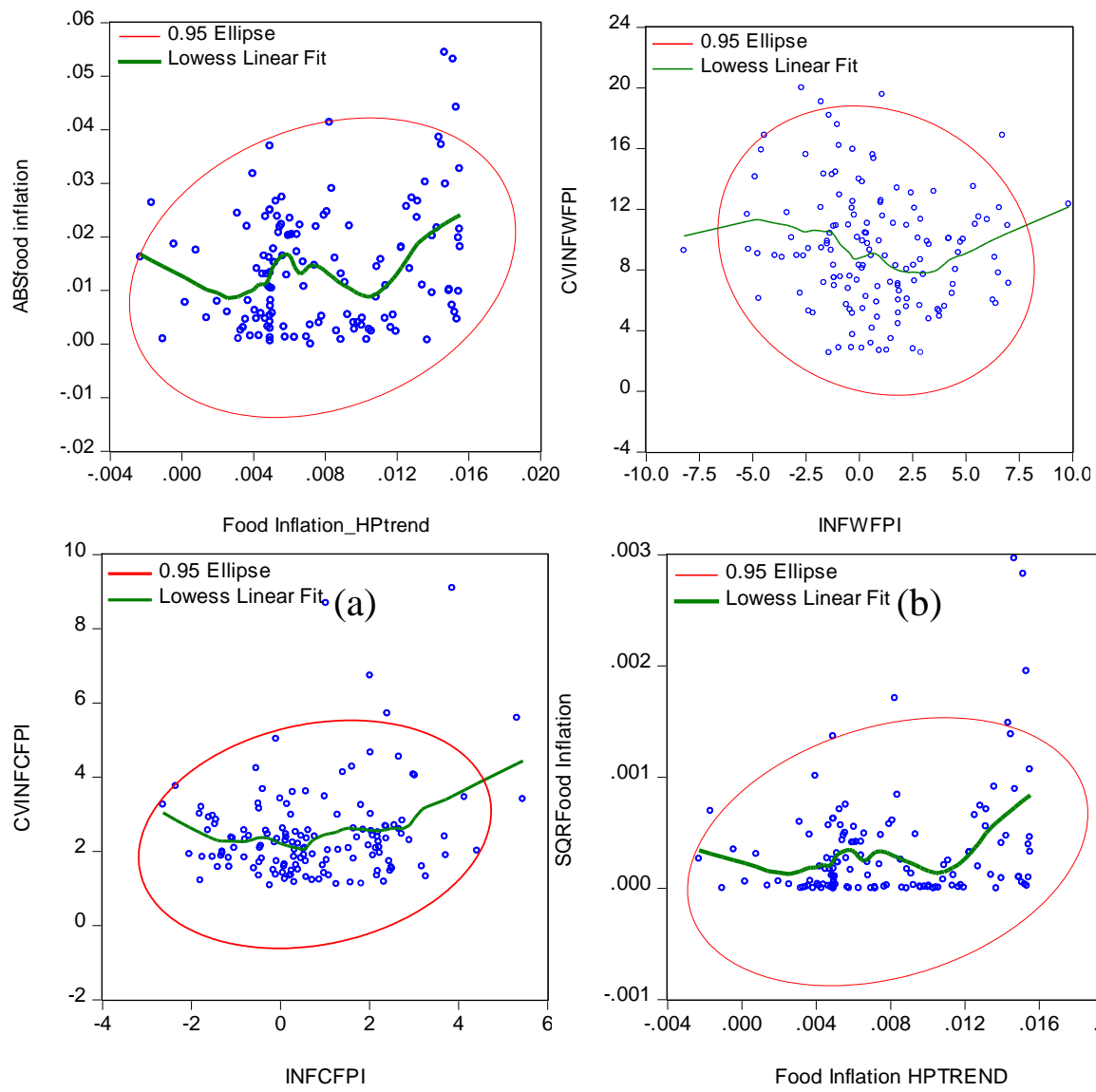

(c)

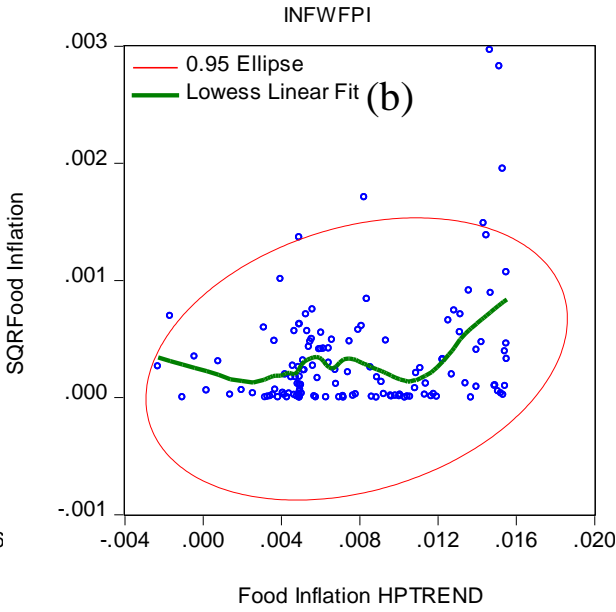

(d)

Figure 2: Food inflation vs Food inflation volatility

Table 1: Unit root test statistics for variables

\begin{tabular}{lccc}
\hline Variables & $\begin{array}{c}\text { Level } \\
\text { intercept only } \\
\text { test statistics } \\
\text { ADF }\end{array}$ & $\begin{array}{c}\text { First difference } \\
\text { intercept only } \\
\text { test statistics } \\
\text { ADF }\end{array}$ & Stationarity \\
\hline INFCFPI & $-9.31(0.000)$ & $-10.389(0.000)$ & $\mathrm{I}(0)$ \\
INFWFPI & $-10.316(0.000)$ & $-12.323(0.000)$ & $\mathrm{I}(0)$ \\
CVINFCFPI & $-3.294(0.016)$ & $-11.087(0.000)$ & $\mathrm{I}(0)$ \\
CVINFWFPI & $-1.119(0.708)$ & $-17.178(0.000)$ & $\mathrm{I}(1)$ \\
\hline
\end{tabular}

Note: at the 5\% significance level, INFCFPI, INFWFPI, CVINFCFPI variables are stationary at level. CVINFWFPI is nonstationary. Unit root test regression model is selected with intercept only. Probability values are in parentheses, $(p)$. 


\section{Causality Relationship between Food Price Inflation and Volatility of Food Price Inflation}

Empirical results of bivariate Granger causality analysis are reported in Table 2. It shows the evidence of causality relationship between food price inflation and food price inflation volatility (conditional variance) series. According to these results, both food inflation series (INFCFPI, INFWFPI) Granger causes its own volatility of inflation series (CVINFCFPI, DCVINFWFPI) in the short run. The p-values of the F test statistics for the null hypothesis that inflation does not Granger cause uncertainty are given in the last column. It indicates that the null hypotheses are rejected at five per cent level. This evidences support the Friedman-Ball research hypothesis.

\section{Bivariate Granger Causality Tests}

Table 2: Bivariate Granger Causality Test between food inflation and food inflation volatility

\begin{tabular}{|c|c|c|}
\hline Null-hypothesis & $F$ statistic & $P$-value \\
\hline $\begin{array}{ll}\text { INFCFPI } & \text { does not Granger cause } \\
\text { CVINFCFPI } & \end{array}$ & $4.702 *$ & 0.010 \\
\hline $\begin{array}{l}\text { CVINFCFPI does not Granger cause } \\
\text { INFCFPI }\end{array}$ & 0.203 & 0.816 \\
\hline $\begin{array}{l}\text { INFWFPI } \\
\text { CVINFCFPI }\end{array}$ & 1.39 & 0.869 \\
\hline $\begin{array}{l}\text { CVINFCFPI does not Granger cause } \\
\text { INFWFPI }\end{array}$ & 0.783 & 0.458 \\
\hline $\begin{array}{l}\text { INFCFPI does not Granger cause } \\
\text { DCVINFWFPI }\end{array}$ & 1.641 & 0.196 \\
\hline $\begin{array}{l}\text { DCVINFWFPI does not Granger cause } \\
\text { INFCFPI }\end{array}$ & 1.099 & 0.335 \\
\hline $\begin{array}{l}\text { INFWFPI does not Granger cause } \\
\text { DCVINFWFPI }\end{array}$ & $4.635^{*}$ & 0.011 \\
\hline $\begin{array}{l}\text { DCVINFWFPI does not Granger cause } \\
\text { INFWFPI }\end{array}$ & 2.534 & 0.082 \\
\hline $\begin{array}{l}\text { DCVINFWFPI does not Granger cause } \\
\text { CVINFCFPI }\end{array}$ & 2.099 & 0125 \\
\hline $\begin{array}{l}\text { CVINFCFPI does not Granger cause } \\
\text { DCVINFWFPI }\end{array}$ & 0.647 & 0.524 \\
\hline
\end{tabular}

Note: CV refers for conditional variance of the food inflation variable, * indicates significance at $5 \%$ level, D refers first difference, INF refers inflation. Note: conditional variance of WFPI was nonstationary. Thus we used first difference of it. Conditional variance of food inflation was stationary.

However, Cukierman-Meltzer (1986) hypothesis; "inflation uncertainty affects inflation", is not supported by the results of our sample using bivariate Granger causality analysis. 
In sum, the results are supportive to the Friedman-Ball hypotheses. Therefore, the Central Bank of Sri Lanka should try to stabilize the inflation rate in the face of inflationary shocks. The results of the study are consistent with the results of Gilbert and Morgan (2010) who say that price levels and price volatilities are likely to be positively associated.

\section{Conclusion}

This paper looks at the relationship between food inflation and its volatility in Sri Lanka. The Granger causality test show strong evidence in line with the Friedman-Ball causal link; inflation causes inflation uncertainty. This implies the need for better monetary stabilization. Economists find the relationship as a central importance for policy analysis. The findings support the notions that an emerging market economy with low to moderate inflation can experience inflation uncertainty. As food inflation and food inflation volatility are interrelated, both could have a significant impact on general inflation. Thus, the findings could be useful to food policy makers to formulate the stabilization programs and inflation targeting policies. These results may guide policy initiatives for achieving and maintaining price stability. It also support the view of adopting inflation targeting policy in Sri Lanka, to reduce the welfare cost of inflation and its related uncertainties.

\section{Limitations of the Study}

It is also worth to note some limitations of the study for future work. Nonlinearity and asymmetric aspects of food price dynamics are not considered in the study. Aggregate food price indices are used in the study for analysis. It would be more informative and useful to use individual food commodities prices. This would help policy planers.

\section{References}

Baillie, R.T., C.F. Chung and M.A. Tieslau (1996a). Analysing Inflation by the Fractionally Integrated ARFIMA-GARCH Model. Journal of Applied Econometrics, 11(1), 23-40.

Baillie, R.T., T. Bollerslev and H.O. Mikkelsen (1996b). Fractionally Integrated Generalized Autoregressive Conditional Heteroskedasticity. Journal of econometrics, 74(1), 3-30.

Ball, L. (1992). Why Does High Inflation Raise Inflation Uncertainty?. Journal of Monetary Economics, 29(3), 371-388.

Ball, L., S.G. Cecchetti and R.J. Gordon (1990). Inflation and Uncertainty at Short and Long Horizons. Brookings Papers on Economic Activity, 215-254. 
Central Bank of Sri Lanka, (2014). Annual Reports of Central Bank of Sri Lanka.

Cukierman, A. and A.H. Meltzer (1986). A Theory of Ambiguity, Credibility, and Inflation under Discretion and Asymmetric Information. Econometrica, 54(5), 1099-1128.

Cukierman, A. and P. Wachtel (1979). Differential Inflationary Expectations and the Variability of the Rate of Inflation: Theory and Evidence. The American Economic Review, 69(4), 595-609.

Daal, E., A. Naka and B. Sanchez (2005). Re-examining Inflation and Inflation Uncertainty in Developed and Emerging Countries. Economics letters, 89(2), 180-186.

Department of Census and Statistics,(2012/13) Household Income and Expenditure Survey.

Evans (1991). Discovering the Link between Inflation Rates and Inflation Uncertainty. Journal of Money Credit, and Banking, 15, 286-301.

Friedman's (1977). Nobel Lecture: Inflation and Unemployment, Journal of Political Eeconomy, 85, 451-72.

Fischer, S., R.E. Hall and J.B. Taylor (1981). Relative Shocks, Relative Price Variability, and Inflation. Brookings Papers on Economic Activity, 1981(2), 381-441.

Grier and Perry (1998). On Inflation and Inflation Uncertainty in the G7 Countries. Journal of International Money and Finance, 17, 671-689.

Holland, A.S. (1993). Uncertain effects of money and the link between the inflation rate and inflation uncertainty. Economic Inquiry, 31(1): 3951.

Holland, S. (1995). Inflation and Uncertainty: Tests for Temporal Ordering. Journal of Money Credit and Banking, 27, 827-837.

Logue, D.E. and T.D Willett (1976). A Note on the Relation between the Rate and Variability of Inflation. Economica, 43(170), 151-158. 31(4), 288301.

Nas, T.F. and M.J. Perry (2000). Inflation, Inflation Uncertainty, and Monetary Policy in Turkey: 1960-1998. Contemporary Economic Policy, 18(2), 170-180.

Okun (1971), The Mirage of Steady Inflation. Brooking Papers on Economic Activity, 2, 485- 498. 
Taylor, J.B. (1981). On the Relation between the Variability of Inflation and the Average Inflation Rate. Paper Presented at the Carnegie-Rochester Conference Series on Public Policy. Memory, or Chaos Processes. University of Illinois, Working Paper No. 98-03.

Wilson (2006). The Links between Inflation, Inflation Uncertainty and Output Growth: New Time Series Evidence from Japan. Journal of Macroeconomics, 28, 609-620. 